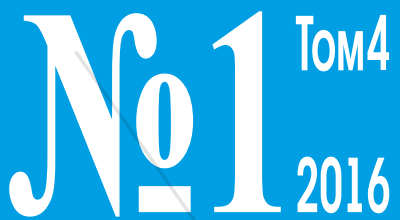

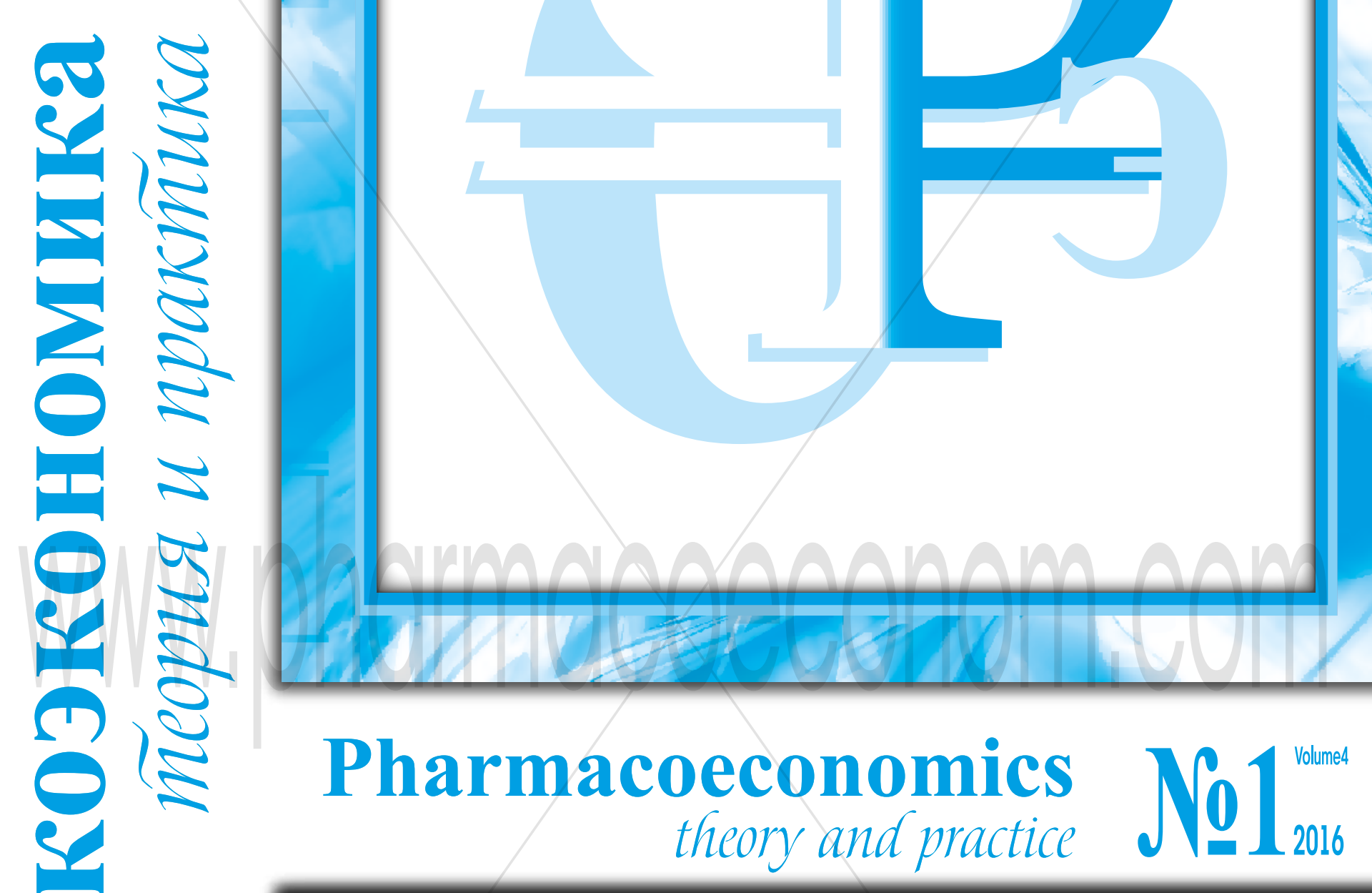

$\square$ МЕТОДОЛОГИЧЕСКИЕ ОСНОВЫ ФАРМАКОЭКОНОМИЧЕСКОГО МОДЕЛИРОВАНИЯ

$\square$ РЕЗУЛЬТАТЫ РОССИЙСКИХ ФАРМАКОЭКОНОМИЧЕСКИХ ИССЛЕДОВАНИЙ

口 МАТЕРИАЛЫ Х НАЦИОНАЛЬНОГО КОНГРЕССА С МЕЖДУНАРОДНЫМ УЧАСТИЕМ «РАЗВИТИЕ ФАРМАКОЭКОНОМИКИ И ФАРМАКОЭПИДЕМИОЛОГИИ В РОССИЙСКОЙ ФЕДЕРАЦИИ» 4-5 апреля 2016 г., г. Нижний Новгород 


\section{АНАЛИЗ ГОСПИТАЛЬНЫХ ЗАТРАТ НА АНТИБАКТЕРИАЛЬНУЮ ТЕРАПИЮ БОЛЬНЫХ ДЕСТРУКТИВНЫМ ПАНКРЕАТИТОМ}

\section{ANALYSIS OF HOSPITAL COSTS OF ANTIBIOTIC THERAPY IN PATIENTS WITH DESTRUCTIVE PANCREATITIS}

Сафиуллин М.Р., Шакирова Д.Х., Красильников Д.М.

Safiullin M.R., Shakirova D.H., Krasilnikov D.M.

ГБОУ ВПО «Казанский государственньй медицинский университет» Минздрава России, 2. Казань

Kazan State Medical University, Kazan

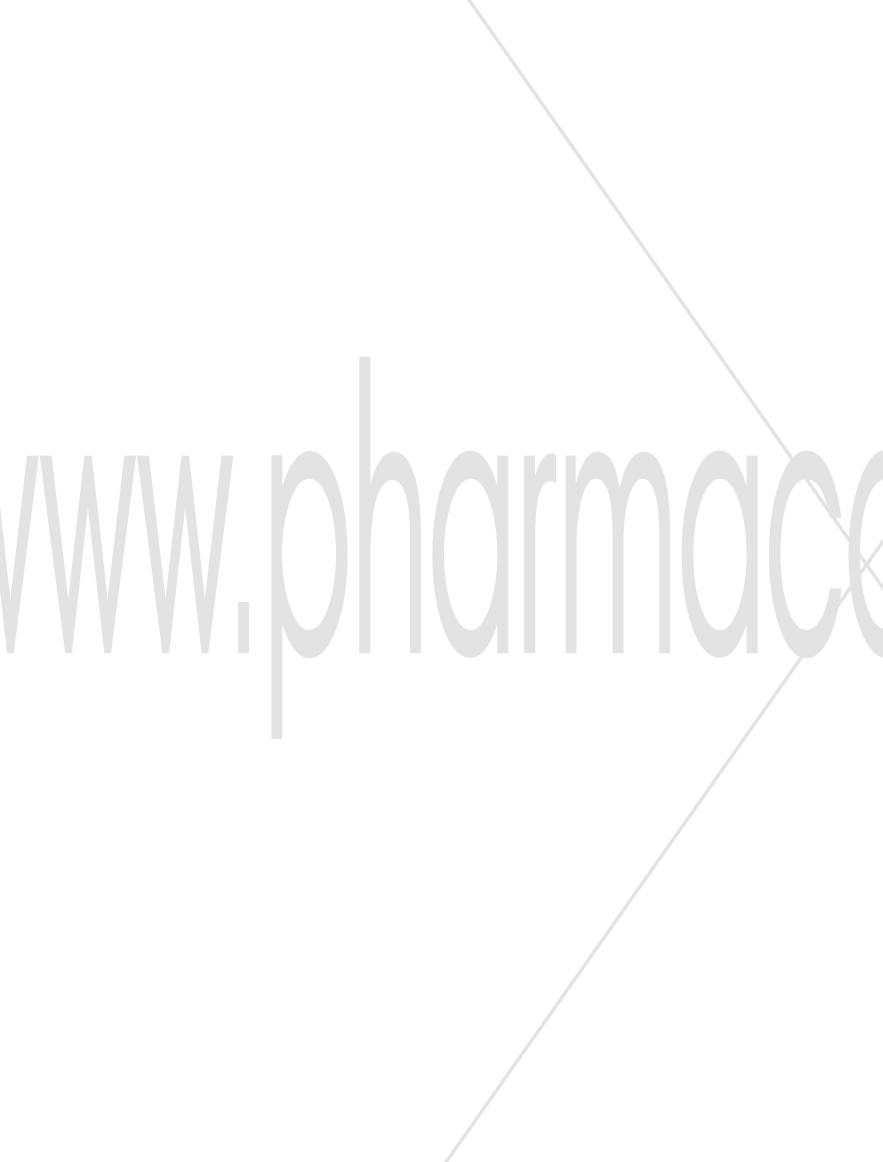

Ключевые слова: анализ затрат, антибактериальная терапия, деструктивный панкреатит.

Цель исследования: анализ затрат на антибактериальную терапию (АБТ) больных деструктивным панкреатитом в условиях стационара.

Материалы и методы: для проведения фрармакоэкономической оценки антибактериальной терапии больных деструктивным панкреатитом в отделении абдоминальной хирургии Республиканской клинической больницы МЗ РТ был проведен контент-анализ 1150 историй болезни и 102 истории болезни Бюро судебно-медицинской экспертизы МЗ РТ за период с 2009 по 2013 годы.

Результаты: было установлено, что фармакотерапия деструктивного панкреатита в условиях стационара назначается в зависимости от формы заболевания, кратности его обострений, от степени интоксикации, характера местных поражений, наличия осложнений и последствий. В отделении абдоминальной хирургии РКБ МЗ РТ используют 16 фармакотерапевтических подходов к лечению данного заболевания, с использованием преимущественно антибиотиков. Из противопротозойных пре- паратов используется только метронидазол. Наиболее дорогостоящие схемы лечения включают препараты меронем и цефтазидим; к наиболее низким по стоимости фрармакотерапиям относится использование гентамицина и ципрофлоксацина. Стоимость лечения меронемом в 450 раз превышает стоимость лечения ципрофлоксацимом и в 1125 раз гентамицином. Стоимость лечения цефтазидимом в 102 раза дороже стоимости лечения ципрофлоксацимом и в 255 раз гентамицином.

Заключение: наиболее экономически эффективной является схема антибактериальной терапии с гентамицином, но учитывая низкую чувствительность и высокую резистентность больных к данному антибиотику, высокая ценовая доступность препарата не является определяющим потребительским свойством, влияющим на объемы закупа. Поэтому при назначении лекарственных препаратов возможны значительные расхождения в стоимости антибактериальной терапии. Тем не менее, оценка затрат на лекарственные препараты необходима для планирования финансовых расходов на закупку медикаментов медицинской организацией, а также для проведения фрармакоэкономического анализа «затраты-эффективность». 